\title{
Excited state molecular structures and reactions directly determined by ultrafast electron diffraction
}

\author{
Jonathan S. Feenstra, Sang Tae Park, and Ahmed H. Zewail ${ }^{a)}$ \\ Laboratory for Molecular Science, Arthur Amos Noyes Laboratory for Chemical Physics, California \\ Institute of Technology, Pasadena, California 91125
}

(Received 31 August 2005; accepted 1 November 2005; published online 14 December 2005)

\begin{abstract}
In this communication, we report on the use of ultrafast electron diffraction to determine structural dynamics of excited states and reaction products of isolated aromatic carbonyls, acetophenone and benzaldehyde. For a $266 \mathrm{~nm}$ excitation, a bifurcation of pathways is structurally resolved, one leading to the formation of the triplet state (quinoid structure) and another to chemical products: for benzaldehyde the products are benzene and carbon monoxide (hydrogen migration and bond rupture) while those for acetophenone are the benzoyl and methyl radicals (bond rupture). The refined structures are compared with those predicted by theory. These dark structures and their radiationless transitions define the reduced energy landscape for complex reactions. () 2005 American Institute of Physics. [DOI: 10.1063/1.2140700]
\end{abstract}

\section{INTRODUCTION}

The importance of structural determination in the dynamics of isolated molecules has been recently demonstrated for the case of pyridines and benzaldehyde. ${ }^{1}$ The reactions were observed to proceed via "dark structures" elusive to spectroscopic methods. Determination of these structures is facilitated by ultrafast electron diffraction (UED) and permits the simultaneous elucidation of the photochemical and photophysical pathways. Here, we report the results of UED experiments performed on two ketones, acetophenone and benzaldehyde, which when excited into their $S_{2}\left(\pi \pi^{*}\right)$ states follow different pathways. We determined the transient and product structures and their different time scales. The results explain the mechanism of bifurcation into physical and chemical pathways.

The aromatic carbonyl compounds benzaldehyde and acetophenone have been studied for decades owing to their intense phosphorescence responses to illumination by ultraviolet radiation. The combination of a phenyl ring and a carbonyl group in conjugation results in a manifold of close, low-lying $n \pi^{*}$ and $\pi \pi^{*}$ excited states. The phosphorescence spectra of both molecules have been characterized in the vapor phase ${ }^{2-4}$ and in matrices. ${ }^{5,6}$ High yields of phosphorescence upon excitation into their $S_{1}\left({ }^{1} n \pi^{*}\right)$ states correspond to a very efficient coupling with the triplet manifold through the non-emitting "dark" $\mathrm{T}_{2}\left({ }^{3} \pi \pi^{*}\right){ }^{7}$ The emission originates from the $\mathrm{T}_{1}\left({ }^{3} n \pi^{*}\right)$ state, although line congestion observed in the vapor phase just above the $\mathrm{T}_{1}$ origin is suggestive of the $\mathrm{T}_{2}\left({ }^{3} \pi \pi^{*}\right)$ state lying within $\sim 1000 \mathrm{~cm}^{-1},{ }^{4,7-10}$ a placement also proposed by theoretical inquiries. ${ }^{11-13}$

Both molecules have been observed to dissociate upon UV irradiation: benzaldehyde along a molecular dissociation pathway leading to closed-shell species, benzene and carbon monoxide, ${ }^{14-21}$ and acetophenone into radical products, ben-

\footnotetext{
a) To whom correspondence should be addressed. Electronic mail: zewail@caltech.edu
}

zoyl and methyl radicals. ${ }^{16,22-24}$ Minor radical production pathways have also been detected from benzaldehyde. ${ }^{25,26}$ In the condensed phase, photophysical studies of benzaldehyde ${ }^{5}$ and acetophenone ${ }^{6}$ (in matrices) and benzaldehyde derivatives $^{27}$ (in solution) indicate that the triplet $\left(\mathrm{T}_{2}\right)$ state becomes the lowest in energy and hence identifiable by its emission. The questions of significance are the following: Are the pathways consecutive in their dynamics? And, what is the nature of the structures involved and in which state do they exist, excited or ground state?

\section{EXPERIMENT}

These experiments were carried out in the apparatus at Caltech. ${ }^{28}$ Some modifications were made in order to accommodate molecules with higher boiling points, such as aromatic carbonyls. Details will be reported in a forthcoming publication. Briefly, an ultrashort electron pulse and an initiating ultrashort optical pulse $(266 \mathrm{~nm})$ intersect with a continuous beam from a free expansion source in mutually perpendicular arrangement. The laser pulses are delayed in order to provide electron diffraction patterns at different times. Then, using the frame-referencing method, ${ }^{29}$ we obtained the changing molecular structures and the time scales involved.

The nozzle temperature was maintained at $210{ }^{\circ} \mathrm{C}$ for benzaldehyde and at $230{ }^{\circ} \mathrm{C}$ for acetophenone to prevent condensation. Both samples were obtained from Aldrich and used without further purification. Data were recorded on a charge-coupled device (CCD) camera assembly, and structural refinement was conducted using our home-designed software with a non-linear least-squares algorithm.

\section{RESULTS AND DISCUSSION}

Two-dimensional diffraction patterns are radially averaged to obtain the data for structural refinement, the modified molecular scattering curves, $s M(s)$; see Ref. 29. By sine Fou- 

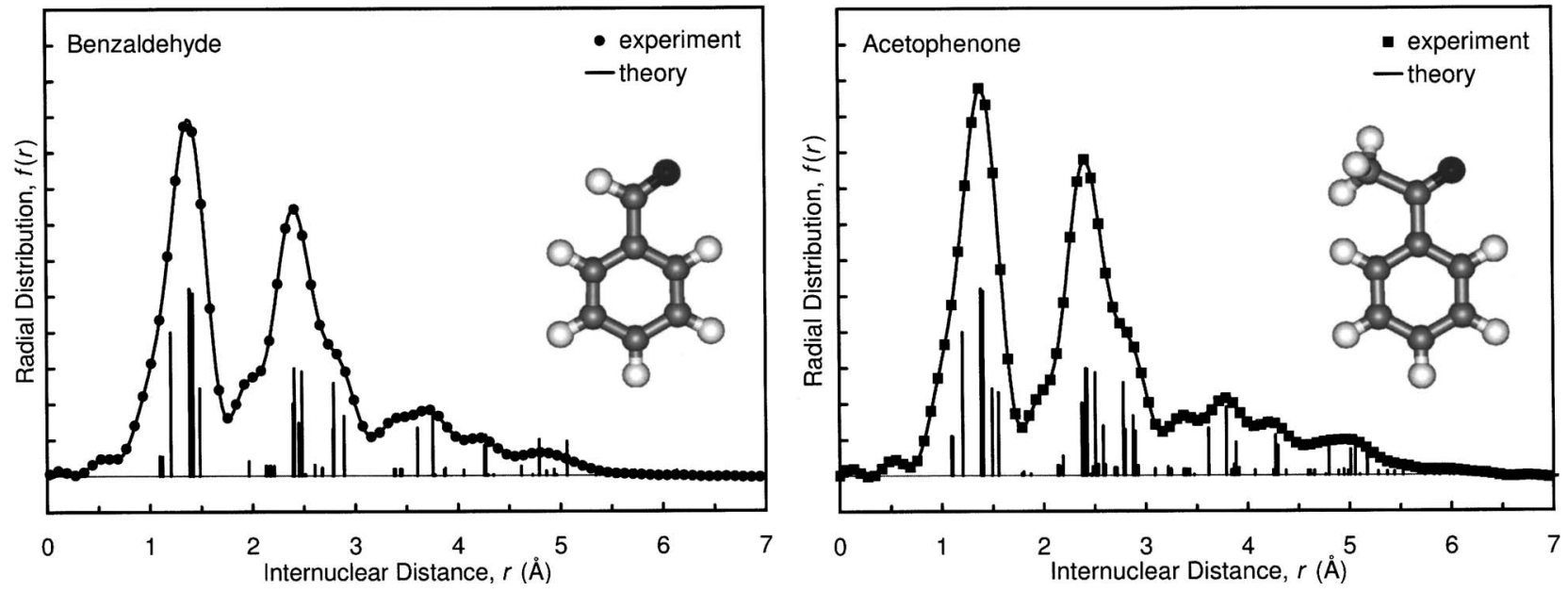

FIG. 1. Radial distributions, $f(r)$. The experimental (filled symbols) and refined theoretical (solid line) of benzaldehyde (left) and acetophenone (right) in their ground states, together with the refined molecular structures. The vertical axis in each plot is the probability density of finding a distance between $r$ and $r$ $+d r$ such that the area of an individual peak, heavily overlapped, is proportional to $\left(Z_{i} Z_{j} / r_{i j}\right)$ for $i$ th and $j$ th nuclei.

rier transforming $s M(s)$ we obtained the radial distribution function $f(r)$, which gives the density of internuclear pairs as a function of distance. At negative times or when the laser excitation is turned off, the structure obtained is that of the ground state. In Fig. 1 we show the experimental $f(r)$ for benzaldehyde and acetophenone ground states together with the theory for the refined structures.

Refined bond distances and angles for benzaldehyde are within $0.02 \AA$ and $1^{\circ}$, respectively, of the structure derived by a previous electron diffraction experiment. ${ }^{30}$ For the phenyl structure we used a $C_{2 v}$ geometry, as did Hargittai and co-workers. ${ }^{30}$ Our density functional theory (DFT) calculations at the B3LYP/6-311G $(d, p)$ level predict that the phenyl ring is almost $C_{2 v}$ symmetric with deviations between opposite-side bond distances ranging from 0.003 to $0.004 \AA$. The carbonyl torsional angle was tested in preliminary fitting and found to remain planar. For the final refinement, the torsional angle was fixed at $0^{\circ}$ keeping the entire carbonyl

TABLE I. The refined structures of ground state benzaldehyde and acetophenone.

\begin{tabular}{|c|c|c|c|}
\hline Molecule & Parameters & Refined value $^{a}$ & $a b$ initio $^{\mathrm{c}}$ \\
\hline \multirow[t]{11}{*}{ Benzaldehyde $^{\mathrm{d}}\left(\mathrm{S}_{0}\right)$} & $\mathrm{C} 1-\mathrm{C} 2, \mathrm{C} 6-\mathrm{C} 1$ & $1.388 \pm 0.004$ & $1.401,1.398$ \\
\hline & $\mathrm{C} 2-\mathrm{C} 3, \mathrm{C} 5-\mathrm{C} 6$ & $1.381 \pm 0.004$ & $1.388,1.392$ \\
\hline & $\mathrm{C} 3-\mathrm{C} 4, \mathrm{C} 4-\mathrm{C} 5$ & $1.417^{\mathrm{b}}$ & $1.398,1.394$ \\
\hline & $\mathrm{C} 1-\mathrm{C} 7$ & $1.480 \pm 0.005$ & 1.481 \\
\hline & $\mathrm{C} 7-\mathrm{O} 8$ & $1.200 \pm 0.002$ & 1.209 \\
\hline & $\mathrm{C} 6-\mathrm{C} 1-\mathrm{C} 2$ & $120.0 \pm 0.7$ & 119.9 \\
\hline & $\mathrm{C} 1-\mathrm{C} 2-\mathrm{C} 3, \mathrm{C} 5-\mathrm{C} 6-\mathrm{C} 1$ & $121.0 \pm 0.9$ & $119.9,120.2$ \\
\hline & $\mathrm{C} 2-\mathrm{C} 3-\mathrm{C} 4, \mathrm{C} 4-\mathrm{C} 5-\mathrm{C} 6$ & $119.1^{\mathrm{b}}$ & $120.0,119.7$ \\
\hline & C3-C4-C5 & $119.9^{b}$ & 120.3 \\
\hline & $\mathrm{C} 2-\mathrm{C} 1-\mathrm{C} 7$ & $120.0^{\mathrm{b}}$ & 120.3 \\
\hline & $\mathrm{C} 1-\mathrm{C} 7-\mathrm{O} 8$ & $126.4 \pm 0.3$ & 124.9 \\
\hline \multirow[t]{13}{*}{ Acetophenone $^{\mathrm{d}}\left(\mathrm{S}_{0}\right)$} & $\mathrm{C} 1-\mathrm{C} 2, \mathrm{C} 6-\mathrm{C} 1$ & $1.407 \pm 0.017$ & $1.401,1.400$ \\
\hline & $\mathrm{C} 2-\mathrm{C} 3, \mathrm{C} 5-\mathrm{C} 6$ & $1.401 \pm 0.019$ & $1.388,1.393$ \\
\hline & $\mathrm{C} 3-\mathrm{C} 4, \mathrm{C} 4-\mathrm{C} 5$ & $1.380^{\mathrm{b}}$ & $1.396,1.393$ \\
\hline & C1-C7 & $1.488 \pm 0.034$ & 1.502 \\
\hline & $\mathrm{C} 7-\mathrm{O} 8$ & $1.198 \pm 0.003$ & 1.215 \\
\hline & C7-C9 & $1.548 \pm 0.016$ & 1.519 \\
\hline & $\mathrm{C} 6-\mathrm{C} 1-\mathrm{C} 2$ & $118.7 \pm 1.4$ & 119.1 \\
\hline & $\mathrm{C} 1-\mathrm{C} 2-\mathrm{C} 3, \mathrm{C} 5-\mathrm{C} 6-\mathrm{C} 1$ & $120.0 \pm 1.1$ & $120.5,120.4$ \\
\hline & $\mathrm{C} 2-\mathrm{C} 3-\mathrm{C} 4, \mathrm{C} 4-\mathrm{C} 5-\mathrm{C} 6$ & $120.7^{\mathrm{b}}$ & $120.0,120.0$ \\
\hline & $\mathrm{C} 3-\mathrm{C} 4-\mathrm{C} 5$ & $120.0^{\mathrm{b}}$ & 120.0 \\
\hline & $\mathrm{C} 2-\mathrm{C} 1-\mathrm{C} 7$ & $120.5^{b}$ & 118.1 \\
\hline & $\mathrm{C} 1-\mathrm{C} 7-\mathrm{O} 8$ & $124.1 \pm 0.4$ & 120.6 \\
\hline & $\mathrm{C} 1-\mathrm{C} 7-\mathrm{C} 9$ & $116.0 \pm 0.4$ & 118.8 \\
\hline
\end{tabular}

${ }^{\mathrm{a}}$ The error bars reported here are $3 \sigma$.

${ }^{\mathrm{b}}$ Dependent variables.

${ }^{\mathrm{c}} A b$ initio structures were obtained at B3LYP/6-311G $(d, p)$.

${ }^{\mathrm{d}}$ Structural parameters for hydrogen were fixed at $a b$ initio values. 


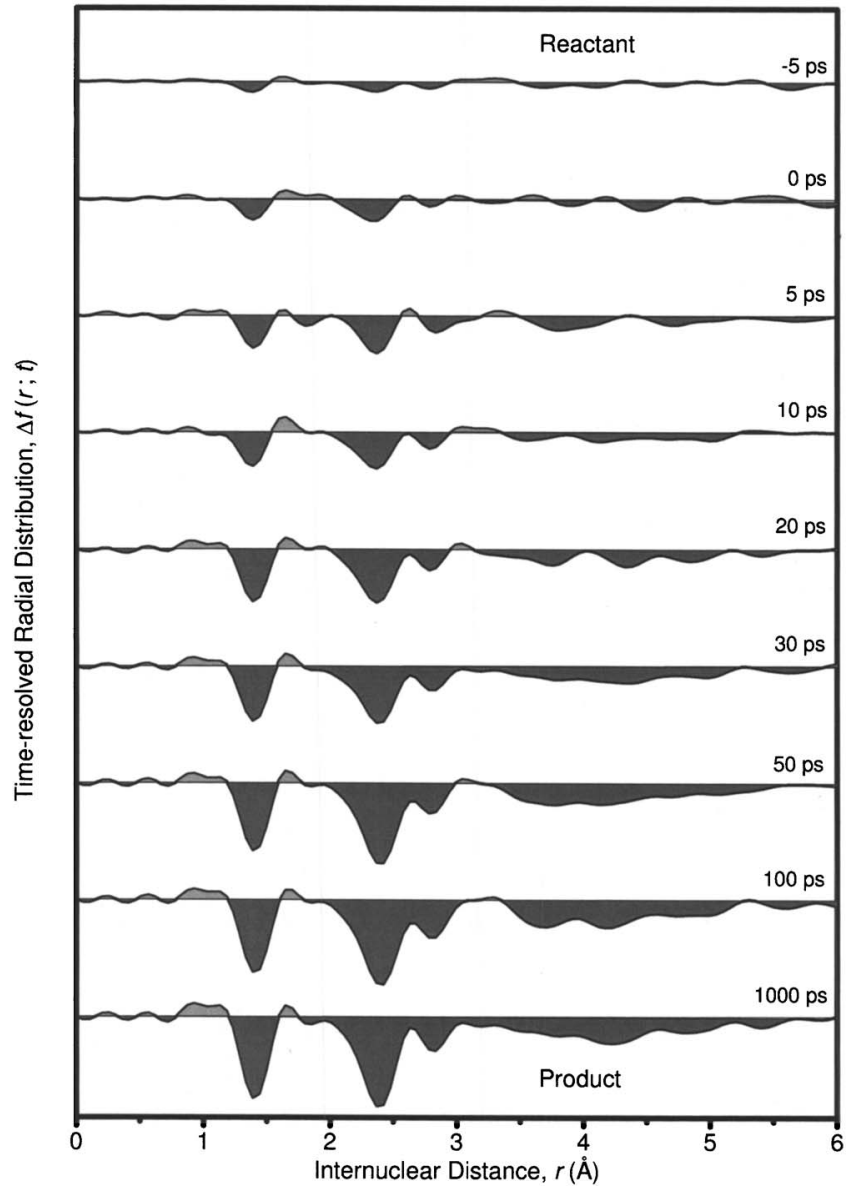

FIG. 2. Time evolution of difference radial distributions, $\Delta f(r ; t)$. Data are presented for benzaldehyde at $266 \mathrm{~nm}$. Dark gray indicates depletion of "old bonds" and light gray indicates emergence of "new bonds."

moiety in the plane of the ring. From the results of the refined structures (Table I), we determine that the $\mathrm{C}-\mathrm{C}$ bond distances range from 1.381 to $1.417 \AA$ within the phenyl ring and $1.480 \AA$ for the ring-carbonyl bond distance. In Fig. 1 the direct $\mathrm{C}-\mathrm{C}$ bonds and nearest neighbor distances are prominent near 1.4 and $2.4 \AA$, respectively, and further cross-ring pairs are seen at distances greater than $3 \AA$.

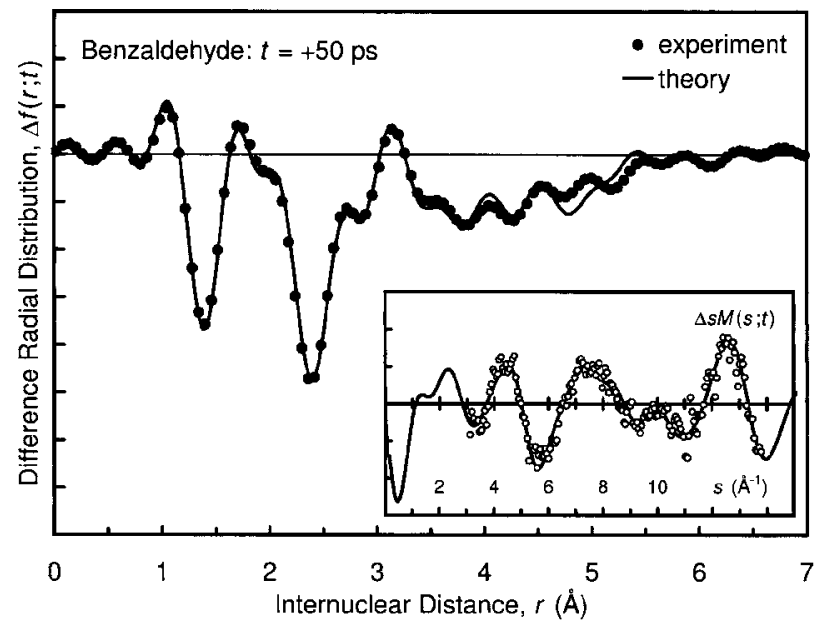

The structure of isolated acetophenone has not been previously reported in the literature. Again, a $C_{2 v}$ geometry was used for the ring system. DFT predicts almost $C_{2 v}$ symmetry; deviations between opposite-side bond distances range from 0.001 to $0.005 \AA$. All refined distances and angles are within the error bars of theory, except for the methyl-carbonyl C-C distance. This bond $(r=1.548 \AA)$ maintains a length $0.029 \AA$ longer than that given by DFT. Aryl C-C bonds are 1.407, 1.401 , and $1.380 \AA$ at their primary, secondary, and tertiary positions (with respect to the carbonyl substituent). The ringcarbonyl single bond was found to be $1.488 \AA$ and the $\mathrm{C}=\mathrm{O}$ bond of the carbonyl $1.198 \AA$. We note that the absolute and relative peak heights in the $f(r)$ of acetophenone are different from benzaldehyde, and follow the increased density of $\mathrm{C}-\mathrm{C}$ (direct bonds), $\mathrm{C} \cdot \mathrm{C}$ (nearest-neighbor), and $\mathrm{C} \cdots \mathrm{C}$ (second-nearest-neighbor) distances. Refined structural parameters are provided in Table I.

In order to observe the structural dynamics, we followed the change of difference $f(r)$ as a function of time. Using frame-referencing to the ground state structure from negative time we obtained $\Delta s M(s ; t)$ and $\Delta f(r ; t)$. The $\Delta f(r ; t)$ data contain both negative contributions from the depletion of "old bonds" and positive contributions from the emergence of "new bonds." Figure 2 displays $\Delta f(r ; t)$ and the changes from $t=-5 \mathrm{ps}$ to $+5 \mathrm{ps}$ and up to $+1000 \mathrm{ps}$. The depletion of internuclear pairs (highlighted in dark gray) is clear at all distances, indicating a major fragmentation and rearrangement of the structure. When the emergence of new structures is significant $(t=+50 \mathrm{ps})$ (see Fig. 3), we refined the product structures. Indeed, analysis of $\Delta s M(s ; t=+50 \mathrm{ps})$ and $\Delta f(r ; t=+50 \mathrm{ps})$ for benzaldehyde gives products of a quinoid structure as well as benzene and carbon monoxide. The refined theory is shown with the data at +50 ps in Fig. 3 .

In contrast, for acetophenone (Fig. 3), the refined structures at the same time after excitation are a triplet-state quinoid structure and products of fragmentation, the benzoyl and methyl radicals released by homolytic bond cleavage. The experimentally determined structures for both benzaldehyde and acetophenone reactions (see Table II), although globally consistent with theory, differ in some bond distances

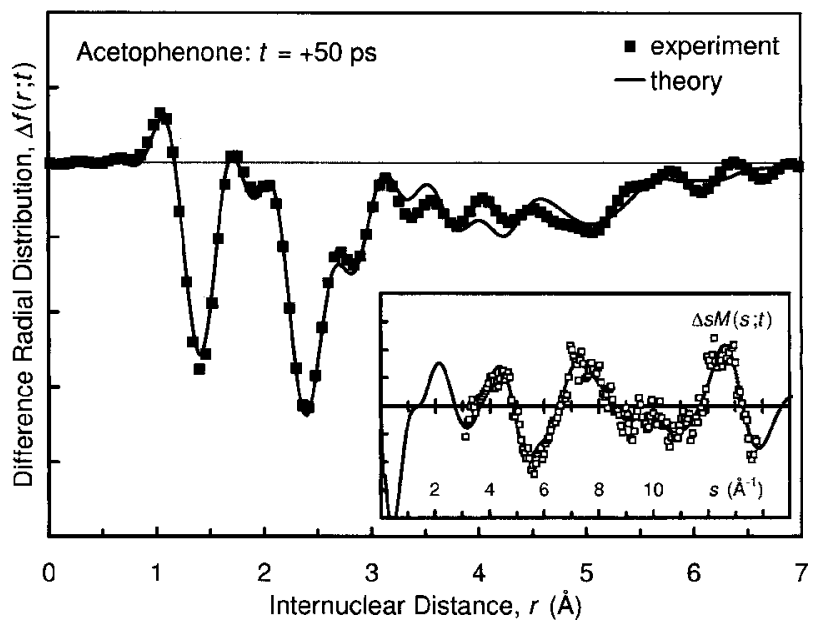

FIG. 3. Difference radial distributions, $\Delta f(r ; t)$. The experimental (filled symbols) and theoretical (solid line) of benzaldehyde (left) and acetophenone (right) at $t=+50 \mathrm{ps}$ upon $266 \mathrm{~nm}$ excitation. The experimental (open symbols) and theoretical (solid line) difference modified molecular scattering curve, $\Delta s M(s ; t)$, of each molecule is shown as an inset. 
TABLE II. The refined structures of excited states and products.

\begin{tabular}{|c|c|c|c|}
\hline Molecule & Parameters & Refined value $^{\mathrm{a}}$ & $a b$ initio $^{c}$ \\
\hline Benzene $^{\mathrm{d}}\left(\mathrm{S}_{0}\right)$ & $\mathrm{C}-\mathrm{C}$ & $1.371 \pm 0.004$ & 1.393 \\
\hline \multirow[t]{11}{*}{ Benzaldehyde $^{\mathrm{d}}\left(\mathrm{T}_{2}\right)$} & $\mathrm{C} 1-\mathrm{C} 2, \mathrm{C} 6-\mathrm{C} 1$ & $1.479 \pm 0.029$ & $1.482,1.474$ \\
\hline & $\mathrm{C} 2-\mathrm{C} 3, \mathrm{C} 5-\mathrm{C} 6$ & $1.322 \pm 0.029$ & $1.362,1.358$ \\
\hline & $\mathrm{C} 3-\mathrm{C} 4, \mathrm{C} 4-\mathrm{C} 5$ & $1.487^{\mathrm{b}}$ & $1.442,1.460$ \\
\hline & $\mathrm{C} 1-\mathrm{C} 7$ & $1.420 \pm 0.045$ & 1.421 \\
\hline & $\mathrm{C} 7-\mathrm{O} 8$ & $1.263 \pm 0.031$ & 1.237 \\
\hline & $\mathrm{C} 6-\mathrm{C} 1-\mathrm{C} 2$ & $115.6 \pm 6.2$ & 117.8 \\
\hline & $\mathrm{C} 1-\mathrm{C} 2-\mathrm{C} 3, \mathrm{C} 5-\mathrm{C} 6-\mathrm{C} 1$ & $122.3 \pm 7.7$ & $120.3,120.7$ \\
\hline & $\mathrm{C} 2-\mathrm{C} 3-\mathrm{C} 4, \mathrm{C} 4-\mathrm{C} 5-\mathrm{C} 6$ & $122.4^{\mathrm{b}}$ & $121.2,120.8$ \\
\hline & $\mathrm{C} 3-\mathrm{C} 4-\mathrm{C} 5$ & $115.0^{\mathrm{b}}$ & 119.2 \\
\hline & $\mathrm{C} 2-\mathrm{C} 1-\mathrm{C} 7$ & $122.2^{\mathrm{b}}$ & 120.9 \\
\hline & $\mathrm{C} 1-\mathrm{C} 7-\mathrm{O} 8$ & $125.4 \pm 2.6$ & 123.1 \\
\hline \multirow[t]{11}{*}{ Benzoyl $^{\mathrm{d}}\left(\mathrm{D}_{0}\right)$} & $\mathrm{C} 1-\mathrm{C} 2, \mathrm{C} 6-\mathrm{C} 1$ & $1.403 \pm 0.024$ & $1.403,1.398$ \\
\hline & $\mathrm{C} 2-\mathrm{C} 3, \mathrm{C} 5-\mathrm{C} 6$ & $1.392^{\mathrm{b}}$ & $1.388,1.391$ \\
\hline & $\mathrm{C} 3-\mathrm{C} 4, \mathrm{C} 4-\mathrm{C} 5$ & $1.370^{\mathrm{b}}$ & $1.397,1.394$ \\
\hline & $\mathrm{C} 1-\mathrm{C} 7$ & $1.487 \pm 0.032$ & 1.482 \\
\hline & $\mathrm{C} 7-\mathrm{O} 8$ & $1.164 \pm 0.009$ & 1.186 \\
\hline & $\mathrm{C} 6-\mathrm{C} 1-\mathrm{C} 2$ & $120.6 \pm 1.1$ & 120.2 \\
\hline & $\mathrm{C} 1-\mathrm{C} 2-\mathrm{C} 3, \mathrm{C} 5-\mathrm{C} 6-\mathrm{C} 1$ & $120.1^{\mathrm{b}}$ & $119.7,119.9$ \\
\hline & $\mathrm{C} 2-\mathrm{C} 3-\mathrm{C} 4, \mathrm{C} 4-\mathrm{C} 5-\mathrm{C} 6$ & $116.2^{\mathrm{b}}$ & $119.9,119.8$ \\
\hline & $\mathrm{C} 3-\mathrm{C} 4-\mathrm{C} 5$ & $127.0^{\mathrm{b}}$ & 120.5 \\
\hline & $\mathrm{C} 2-\mathrm{C} 1-\mathrm{C} 7$ & $119.7^{\mathrm{b}}$ & 120.5 \\
\hline & $\mathrm{C} 1-\mathrm{C} 7-\mathrm{O} 8$ & $130.6 \pm 2.7$ & 128.5 \\
\hline \multirow[t]{13}{*}{ Acetophenone $^{\mathrm{d}}\left(\mathrm{T}_{2}\right)$} & $\mathrm{C} 1-\mathrm{C} 2, \mathrm{C} 6-\mathrm{C} 1$ & $1.495 \pm 0.014$ & $1.487,1.474$ \\
\hline & $\mathrm{C} 2-\mathrm{C} 3, \mathrm{C} 5-\mathrm{C} 6$ & $1.349 \pm 0.021$ & $1.358,1.356$ \\
\hline & $\mathrm{C} 3-\mathrm{C} 4, \mathrm{C} 4-\mathrm{C} 5$ & $1.441^{\mathrm{b}}$ & $1.446,1.462$ \\
\hline & $\mathrm{C} 1-\mathrm{C} 7$ & $1.460^{\mathrm{b}}$ & 1.446 \\
\hline & $\mathrm{C} 7-\mathrm{O} 8$ & $1.214 \pm 0.018$ & 1.224 \\
\hline & $\mathrm{C} 7-\mathrm{C} 9$ & $1.530^{\mathrm{b}}$ & 1.516 \\
\hline & $\mathrm{C} 6-\mathrm{C} 1-\mathrm{C} 2$ & $117.3 \pm 1.3$ & 117.4 \\
\hline & $\mathrm{C} 1-\mathrm{C} 2-\mathrm{C} 3, \mathrm{C} 5-\mathrm{C} 6-\mathrm{C} 1$ & $120.7^{\mathrm{b}}$ & $120.7,120.8$ \\
\hline & $\mathrm{C} 2-\mathrm{C} 3-\mathrm{C} 4, \mathrm{C} 4-\mathrm{C} 5-\mathrm{C} 6$ & $119.7^{\mathrm{b}}$ & $121.1,121.1$ \\
\hline & $\mathrm{C} 3-\mathrm{C} 4-\mathrm{C} 5$ & $121.9^{\mathrm{b}}$ & 118.8 \\
\hline & $\mathrm{C} 2-\mathrm{C} 1-\mathrm{C} 7$ & $121.3^{\mathrm{b}}$ & 119.2 \\
\hline & $\mathrm{C} 1-\mathrm{C} 7-\mathrm{O} 8$ & $126.0 \pm 7.9$ & 119.8 \\
\hline & $\mathrm{C} 1-\mathrm{C} 7-\mathrm{C} 9$ & $117.0^{\mathrm{b}}$ & 120.4 \\
\hline
\end{tabular}

${ }^{\mathrm{a}}$ The error bars reported here are $3 \sigma$.

${ }^{\mathrm{b}}$ Dependent variables.

${ }^{\mathrm{c}} A b$ initio structures were obtained at $\mathrm{B} 3 \mathrm{LYP} / 6-311 \mathrm{G}(d, p)$ for benzene, carbon monoxide, methyl, and benzoyl. $\operatorname{CASSCF}(9,10) / 6-31 \mathrm{G}(d)$ was used for the excited state $\left(\mathrm{T}_{2}\right)$ of benzaldehyde, and $\operatorname{CASSCF}(9,10) / 6$ $-311 \mathrm{G}(d, p)$ for the excited state $\left(\mathrm{T}_{2}\right)$ of acetophenone.

${ }^{\mathrm{d}}$ Structural parameters for hydrogen and carbon monoxide were fixed at ab initio values.

and angles. The truly $\pi \pi^{*}$ nature of the quinoidal structure is exemplified by unperturbed double and single bonds in the ring - unlike in the aromatic structure with its six nearlyequal bond distances. These changes are a clear consequence of the loss of aromaticity upon passage to the $\pi \pi^{*}$ excited state. Calculations in the literature ${ }^{13}$ and our own indicate that $\mathrm{T}_{1}$ is an $n \pi^{*}$ state with excitation largely in the carbonyl group (a longer $\mathrm{C}=\mathrm{O}$ bond being the only significant structural deviation from the ground state). Furthermore, calculations show that $\mathrm{T}_{2}$ is $\pi \pi^{*}$ with the excitation causing an alternation of single and double bonds in the phenyl ring. Both structures were compared with the data and only the latter fit well. A thorough account of this will be contained in a forthcoming publication.
For benzaldehyde, data were taken at multiple timepoints up to $1 \mathrm{~ns}$ delay. The final product structures were compared to each of these data points in order to assess the time-dependent fractional contributions. From this information the rate constants for excited triplet formation and molecular dissociation were obtained to be $2.4 \times 10^{10} \mathrm{~s}^{-1}$ and $1.6 \times 10^{10} \mathrm{~s}^{-1}$, respectively. Additionally, benzene formation is not seen to deplete the triplet population, confirming that both physical and chemical pathways occur via bifurcation from a single state. Owing to the $<1$ ps decay time of the initial $\mathrm{S}_{2}$ state, known from photoelectron measurements, ${ }^{31}$ the bifurcating state is likely the vibrationally-excited $S_{1}$ after internal conversion. The existence of $\mathrm{S}_{1}\left({ }^{1} n \pi^{*}\right)$, as well as 

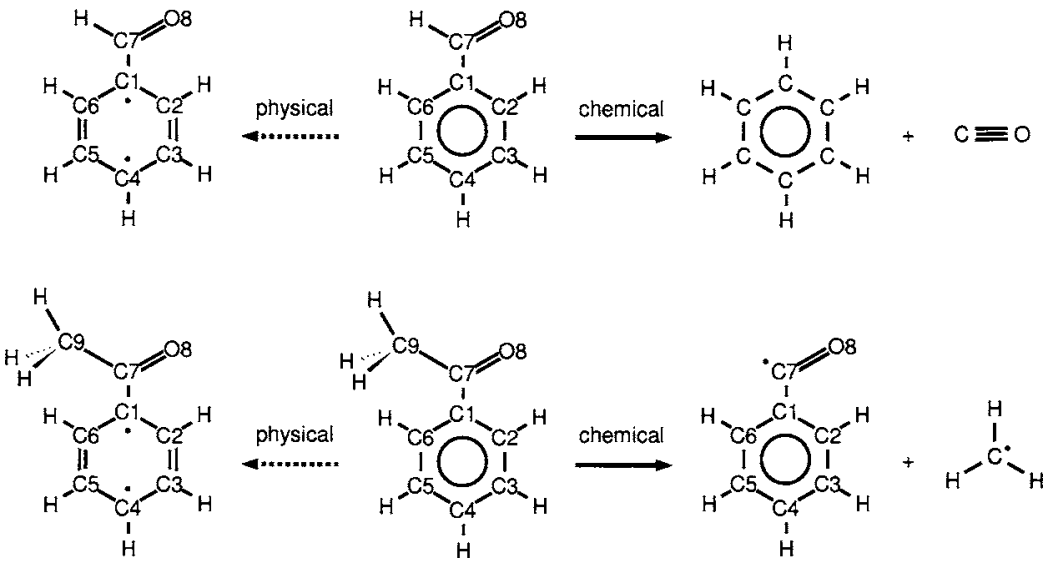

FIG. 4. The structures determined and the bifurcation channels of physical and chemical pathways.

the phosphorescing $\mathrm{T}_{1}\left({ }^{3} n \pi^{*}\right)$, states in our data could not be confirmed due to their structural similarity with ground state benzaldehyde (for the $a b$ initio structures, see Ref. 13). No depletion of $\mathrm{T}_{2}\left({ }^{3} \pi \pi^{*}\right)$ is observed, so the population of $\mathrm{T}_{1}$ $\left({ }^{3} n \pi^{*}\right)$ is probably negligible on our time-scale. Reactions from $\mathrm{T}_{2}$ have been reported to occur in nanoseconds. ${ }^{21}$

In the case of benzaldehyde, the formation of $\mathrm{T}_{2}$ had stabilized at +50 ps while the molecular dissociation channel reached a steady state at +100 ps. With acetophenone the behavior is similar in that the $T_{2}$ population reaches steady state at $+50 \mathrm{ps}$ but the relative fraction of fragmentation channel increases at +100 ps. Thus, the bifurcation into photophysical and photochemical channels in acetophenone is similar to benzaldehyde, presumably also from the $S_{1}$ state. For benzaldehyde we established the nature of the temporal rise and measured a time constant of 42 ps for the tripletformation channel and 65 ps for the molecular dissociation channel; for acetophenone diffraction data were only obtained at three time points $(-100,+50$, and $+100 \mathrm{ps})$.

Structural dynamics on the energy landscape for these prototypical aromatic carbonyls can now be pictured. Bifurcation into physical and chemical channels (see Fig. 4) results following excitation into the excited $\pi \pi^{*}\left(\mathrm{~S}_{2}\right)$ state and ultrafast internal conversion. ${ }^{31}$ The physical channel in both benzaldehyde and acetophenone ultimately results in a triplet state whose structure is quinoid. The chemical channels are vastly different. In benzaldehyde a reaction leading to molecular, closed-shell dissociation products is observed, while in acetophenone radical products result. Analogy can be drawn between these two systems and two related carbonyls, the well-studied acetone and acetaldehyde. The ketone (acetone) dynamics show a Norrish type-I radical cleavage but with precursor nuclear motions and energy redistribution. ${ }^{32}$ The aldehyde (acetaldehyde) may undergo radical cleavage or molecular dissociation to yield methane and carbon monoxide. ${ }^{33}$ The difference in the chemistry stems from the relative ease by which the hydrogen may be captured by a nearby nuclear center during a large-amplitude wagging. Moreover, the internal conversion to the $\mathrm{S}_{1}\left({ }^{1} n \pi^{*}\right)$ state results in weakening of the ring-carbonyl $\mathrm{C}-\mathrm{C}$ bond. Our calculations predict a transition state for the reaction with a hydrogen atom shared between two carbon centers.

Determination of the structures of excited states and transient reaction products is critical to the mechanism as discussed above. It is apparent that the nature of the landscape cannot be understood without resolving and examining the dark structures, and their radiationless transitions, involved in the multiple pathways of physical and chemical processes. The sensitivity and resolutions reached here promise other applications to systems of unique reactivity. ${ }^{34}$

\section{ACKNOWLEDGMENTS}

This work was supported by the National Science Foundation and the Air Force Office of Scientific Research. The authors would also like to thank Professor Robert Huber ${ }^{35}$ for a private communication regarding acetaldehyde channels $\left(\mathrm{CH}_{4}+\mathrm{CO} ; \mathrm{CH}_{3}+\mathrm{HCO}\right.$; and $\mathrm{H}+\mathrm{CH}_{3} \mathrm{CO}$, depending on excitation energy) and his proposal for UED of acetaldehyde, and Dr. Shoujun $\mathrm{Xu}$ for his assistance in the design of the inlet system of the apparatus.

${ }^{1}$ R. Srinivasan, J. S. Feenstra, S. T. Park, S. Xu, and A. H. Zewail, Science 307, 558 (2005).

${ }^{2}$ Y. Hirata and E. C. Lim, J. Chem. Phys. 72, 5505 (1980).

${ }^{3}$ Y. Hirata and E. C. Lim, Chem. Phys. Lett. 71, 167 (1980).

${ }^{4}$ M. Koyanagi and L. Goodman, Chem. Phys. 39, 237 (1979).

${ }^{5}$ H. Hayashi and S. Nagakura, Mol. Phys. 27, 969 (1974).

${ }^{6}$ M. Koyanagi, R. J. Zwarich, and L. Goodman, J. Chem. Phys. 56, 3044 (1972).

${ }^{7}$ M. Kiritani, T. Yoshii, N. Hirota, and M. Baba, J. Phys. Chem. 98, 11265 (1994).

${ }^{8}$ E. Villa, A. Amirav, W. Chen, and E. C. Lim, Chem. Phys. Lett. 147, 43 (1988).

${ }^{9}$ N. Ohmori, T. Suzuki, and M. Ito, J. Phys. Chem. 92, 1086 (1988).

${ }^{10}$ O. Sneh and O. Cheshnovsky, J. Phys. Chem. 95, 7154 (1991).

${ }^{11}$ L. Goodman and I. Ozkan, Chem. Phys. Lett. 61, 216 (1979).

${ }^{12}$ V. Molina and M. Merchán, J. Phys. Chem. A 105, 3745 (2001).

${ }^{13}$ Y.-W. Wang, H.-Y. He, and W.-H. Fang, J. Mol. Struct.: THEOCHEM 634, 281 (2003).

${ }^{14}$ M. Berger, I. L. Goldblatt, and C. Steel, J. Am. Chem. Soc. 95, 1717 (1973).

${ }^{15}$ U. Brühlmann, M. Monella, P. Russegger, and J. R. Huber, Chem. Phys. 81, 439 (1983)

${ }^{16}$ M. B. Robin and N. A. Kuebler, J. Am. Chem. Soc. 97, 4822 (1975).

${ }^{17}$ S. R. Long, J. T. Meek, P. J. Harrington, and J. P. Reilley, J. Chem. Phys. 78, 3341 (1983).

${ }^{18}$ J. J. Yang, D. A. Gobeli, and M. A. El-Sayed, J. Phys. Chem. 89, 3426 (1985)

${ }^{19}$ J. J. Yang, D. A. Gobeli, R. S. Pandolfl, and M. A. El-Sayed, J. Phys. Chem. 87, 2255 (1983).

${ }^{20}$ A. V. Polevoi, V. M. Matyuk, G. A. Grigor'eva, and V. K. Potapov, Khim. Vys. Energ. 18, 195 (1984).

${ }^{21}$ C. R. Silva and J. P. Reilley, J. Phys. Chem. A 101, 7934 (1997).

${ }^{22}$ M. Berger and C. Steel, J. Am. Chem. Soc. 97, 4817 (1975).

${ }^{23}$ H.-Q. Zhao, Y.-S. Cheung, C.-L. Liao, C.-X. Liao, C. Y. Ng, and W.-K. 
Li, J. Chem. Phys. 107, 7230 (1997).

${ }^{24}$ S. Anand, M. M. Zamari, G. Menkir, R. J. Levis, and H. B. Schlegel, J. Phys. Chem. A 108, 3162 (2004).

${ }^{25}$ V. S. Antonov, I. N. Knyazev, V. S. Letokhov, V. M. Matyuk, V. G. Movshev, and V. K. Potapov, Khim. Vys. Energ. 12, 476 (1978).

${ }^{26}$ L. Zhu and T. J. Cronin, Chem. Phys. Lett. 317, 227 (2000).

${ }^{27}$ S. Srivistava, E. Yourd, and J. P. Toscano, J. Am. Chem. Soc. 120, 6173 (1998).

${ }^{28}$ H. Ihee, V. A. Lobastov, U. Gomez, B. M. Goodson, R. Srinivasan, C.-Y. Ruan, and A. H. Zewail, Science 291, 458 (2001)

${ }^{29}$ R. Srinivasan, V. A. Lobastov, C.-Y. Ruan, and A. H. Zewail, Helv. Chim. Acta 86, 1763 (2003), and references therein.
${ }^{30}$ K. B. Borisenko, C. W. Bock, and I. Hargittai, J. Phys. Chem. 100, 7426 (1996).

${ }^{31}$ S.-H. Lee, K.-C. Tang, I.-C. Chen, M. Schmitt, J. P. Shaffer, T. Schultz, J. G. Underwood, M. Z. Zgierski, and A. Stolow, J. Phys. Chem. A 106, 8979 (2002)

${ }^{32}$ E. W.-G. Diau, C. Kötting, and A. H. Zewail, ChemPhysChem 2, 273 (2001).

${ }^{33}$ J. G. Calvert and J. N. Pitts, Jr., Photochemistry (Wiley, New York, 1967).

${ }^{34}$ J. Michl and V. Bonačić-Koutecký, Electronic Aspects of Organic Photochemistry (Wiley, New York, 1990).

${ }^{35}$ J. R. Huber, Chem. Phys. Lett. 377, 481 (2003). 